\title{
Routine screening for Coxiella burnetii infection during pregnancy: a clustered randomised controlled trial during an outbreak, the Netherlands, 2010
}

J M Munster (j.munster@umcg.nl)1,2,3, A C Leenders4, C J Hamilton5, J C Meekelenkamp4, P M Schneeberger4, W van der Hoek ${ }^{6}$,

A Rietveld7, E de Vries ${ }^{8}$, R P Stolk ${ }^{3}$, J G Aarnoudse ${ }^{2}$, E Hak Hal, $^{1,3}$

1. University of Groningen, University Center for Pharmacy, PharmacoEpidemiology \& PharmacoEconomics, Groningen, the Netherlands

2. University of Groningen, University Medical Center Groningen, Department of Obstetrics and Gynaecology, Groningen, the Netherlands

3. University of Groningen, University Medical Center Groningen, Department of Epidemiology, Groningen, the Netherlands

4. Jeroen Bosch Hospital, Department of Medical Microbiology and Infection Prevention, 's-Hertogenbosch, the Netherlands

5. Jeroen Bosch Hospital, Department of Obstetrics and Gynaecology, 's-Hertogenbosch, the Netherlands

6. National Institute for Public Health and the Environment, Centre for Infectious Disease Control, Epidemiology and Surveillance Unit, Bilthoven, the Netherlands

7. Municipal Health Service "Hart voor Brabant", "s-Hertogenbosch, the Netherlands

8. Jeroen Bosch Hospital, Department of Paediatrics, 's-Hertogenbosch, the Netherlands

Citation style for this article:

Munster JM, Leenders AC, Hamilton CJ, Meekelenkamp JC, Schneeberger PM, van der Hoek W, Rietveld A, de Vries E, Stolk RP, Aarnoudse JG, Hak E. Routine screening for Coxiella burnetii infection during pregnancy: a clustered randomised controlled trial during an outbreak, the Netherlands, 2010. Euro Surveill. 2013;18(24):pii=20504. Available online: http://www.eurosurveillance.org/ViewArticle.aspx?Articleld=20504

Article submitted on 12 December 2012 / published on 13 June 2013

Between 2007 and 2010, the Netherlands experienced one of the largest outbreaks of $Q$ fever. Since asymptomatic Coxiella burnetii infection has been associated with maternal and obstetric complications, evidence about the effectiveness of routine screening during pregnancy in outbreak areas is needed. We performed a clustered randomised controlled trial during the Dutch outbreak, in which 55 midwife centres were randomised to recruit pregnant women for an intervention or control strategy. In both groups a serum sample was taken between 20 and 32 weeks of gestation. In the intervention group $(n=536)$, the samples were analysed immediately by indirect immunofluorescence assay for the presence of IgM and IgG (phase I/ II) and treatment was given during pregnancy in case of an acute or chronic infection. In the control group $(n=693)$, sera were frozen for analysis after delivery. In both groups $15 \%$ were seropositive. In the intervention group $2.2 \%$ of the women were seropositive and had an obstetric complication, compared with $1.4 \%$ in the control group (Odds ratio: 1.54 (95\% confidence interval 0.60-3.96)). During a large $Q$ fever outbreak, routine $C$. burnetii screening starting at 20 weeks of gestation was not associated with a relevant reduction in obstetric complications and should therefore not be recommended.

\section{Introduction}

Viral, bacterial and parasitic infections during pregnancy, such as human immunodeficiency virus, syphilis and toxoplasmosis, are a threat to both maternal and foetal health, even if the infection is asymptomatic. Routine screening for some of these infectious diseases is therefore recommended for all pregnant women [1]. Due to several outbreaks, the incidence of $\mathrm{Q}$ fever, a zoonosis caused by the bacterium Coxiella burnetii, has been increasing in the Netherlands and some other European countries since 2007 [2,3]. Most of the infected individuals are either asymptomatic or present with a mild influenza-like illness. However, C. burnetii may pose a serious threat to pregnant women because of the increased risk of chronic $Q$ fever, often complicated by endocarditis [4-6]. In addition, both symptomatic and asymptomatic $C$. burnetii infection during pregnancy have been associated with obstetric complications due to placentitis, including preterm delivery, intrauterine growth restriction and foetal death $[7,8]$. Because most infected pregnant women remain asymptomatic [9], routine serological screening during an outbreak could be of great value to prevent chronic maternal infections and obstetric complications, but evidence from randomised trials is lacking. Since the Dutch $Q$ fever outbreak has been unique in size, with over 3,500 cases over three years [10], we had the opportunity to perform a clustered randomised controlled trial (RCT) to assess the effectiveness of large-scale routine serological screening for $C$. burnetii infection of pregnant women during a $Q$ fever outbreak.

\section{Methods}

We conducted a clustered RCT in which primary care midwife centres were randomised to recruit pregnant women either for the intervention or for the control group (Figure 1).

The study was conducted according to the principles of the Declaration of Helsinki, and the study protocol was approved by the Medical Ethical Review Board of the 
Flow chart of the study protocol, study on screening for Coxiella burnetii infection during pregnancy, the Netherlands, 2010 $(n=1,229)$

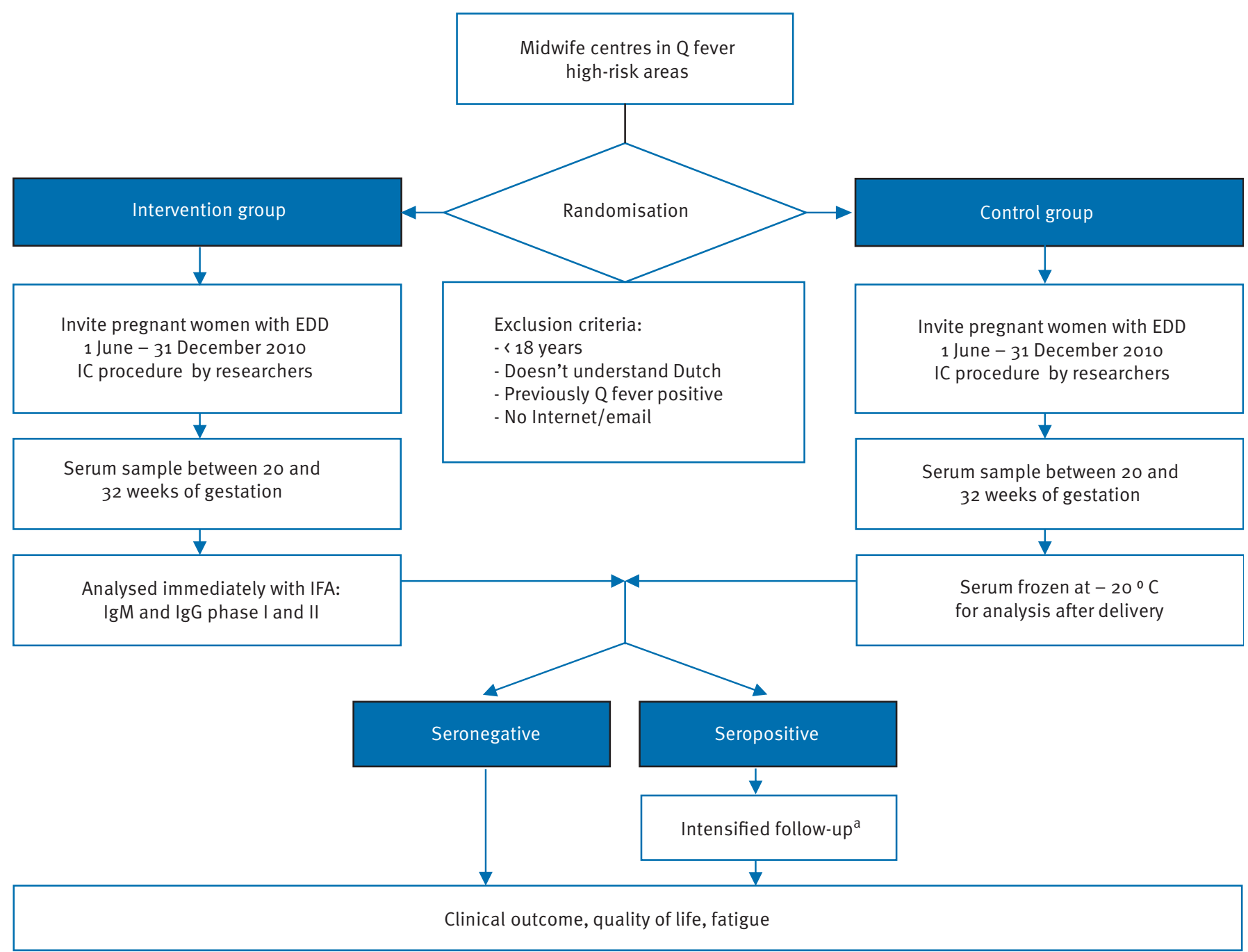

EDD: estimated date of delivery; IC: informed consent; IFA: indirect immunofluorescence assay.

a For the intervention group intensified serological follow-up and pregnancy monitoring with possible antibiotic treatment were performed during pregnancy under supervision of secondary healthcare. For the control group serological follow-up was performed after pregnancy in collaboration with the patients' general practitioner.

University Medical Center Groningen. All participants gave written informed consent.

The study was set in $Q$ fever high-risk areas in the Netherlands. High-risk areas were defined as municipalities with a $Q$ fever incidence of more than 50 cases per 100,000 inhabitants in 2009 or more than 20 cases per 100,000 inhabitants in the first half of 2010 , according to the official Dutch surveillance data [11].

\section{Randomisation}

Randomisation was stratified by the number of goat farms in the municipality (up to seven or more than seven), a measure of the risk associated with contracting a $C$. burnetii infection according to a study by van der Hoek et al. [12], and by the size of the midwife centre (up to 300 or more than 300 pregnant women under care per year). Since this was an open-label study, midwives, other healthcare workers, participants and the researchers were aware of the outcome of the randomisation.

Inclusion and exclusion criteria for participants Pregnant women, 18 years of age or older, with an estimated date of delivery between 1 June and 31 December 2010, supervised by a midwife in primary healthcare 
were eligible for inclusion. In the Netherlands, midwives working in primary healthcare are only allowed to supervise low-risk, singleton pregnancies. Using this criterion, women with a known increased risk for complicated pregnancy outcome beforehand e.g. twin pregnancies or pregnant women with chronic illnesses, were excluded. Moreover, women who did not have access to Internet or an email address were also excluded because data collection was web-based. In the Netherlands, $91 \%$ of the households have Internet access [13]. The remaining $9 \%$ consist of elderly or single occupants, so very little exclusion from this restriction was expected. In addition, women who were unable to understand Dutch, unable to give informed consent, or were already diagnosed with $\mathrm{Q}$ fever, were ineligible for participation in the study. Since (diagnostic) testing was not performed on a regular basis before the study, very little exclusion from this restriction was expected also.

\section{Intervention group}

Participants in the intervention group were asked for a serum sample between 20 and 32 weeks of gestation to be screened for infection with $C$. burnetii. The samples were analysed immediately by indirect immunofluorescence assay (IFA) in the laboratory of the Jeroen Bosch Hospital, 's-Hertogenbosch, the Netherlands. Both immunoglobulin (Ig)M and IgG against $C$. burnetii phase I and phase II antigens (Nine Mile strain) were measured according to the manufacturer's instructions (Focus Diagnostics, Cypress, CA, USA). Each run included a positive and a negative control. For every positive sample the titre was determined to reduce the chance of false positivity. In line with the cut-off values used in the clinical setting for the diagnosis of $Q$ fever in symptomatic patients, titres $\geq 1: 32$ were considered positive [14]. Whenever there was IgM seropositivity, follow-up was performed two to four weeks after the screening sample had been taken. A probable acute infection was defined as the presence of positive titres of IgM (phase I and/or II) in the first screening sample. A proven acute infection was defined as positive titres for IgM accompanied with (rising) titres of IgG phase I and/or II during follow-up. A previous infection was defined as the presence of only IgG (phase I and/or II) in the screening sample. A probable chronic $C$. burnetii infection was defined as an antibody titre of IgG phase $\mathrm{I} \geq 1: 1,024$ [15].

In seronegative women, standard care was provided. In case of a (probable) acute or chronic C. burnetii infection, women were referred to an obstetrician and intensified serological and obstetric follow-up according to the local hospital protocol took place. Antibiotic treatment (cotrimoxazole (960 mg twice daily) or erythromycin (500 mg twice daily to four times a day, depending on the term of pregnancy) for at least five weeks) was started in collaboration with the local medical microbiologist in any case of a proven acute or chronic infection. In case of a previous infection, no treatment was started, but serological analysis was repeated in the third trimester of pregnancy to exclude reactivation or chronic infection.

\section{Control group}

Women in the control group were also asked for a serum sample between 20 and 32 weeks of gestation. These samples were centrally stored in the laboratory of the Jeroen Bosch Hospital at $-20^{\circ} \mathrm{C}$ and were analysed for antibodies against $C$. burnetii after delivery, as the intervention group. In this group, distinguishing a probable and proven acute infection was impossible since follow-up serology during pregnancy was not performed. In case of a positive test, the participant's general practitioner was advised to perform an extra serological analysis after delivery to exclude a probable chronic infection.

\section{Both groups}

If symptoms compatible with $\mathrm{Q}$ fever occurred during pregnancy, these participants were advised to visit a physician for regular diagnostics.

\section{Outcome measures}

The primary endpoint of the study pertained to the individual level and was a composite measure of a maternal or obstetric complication in seropositive women. A maternal complication was defined as a serological profile suggesting a probable chronic infection. Obstetric complications included preterm delivery (defined as delivery 137 weeks of gestation), a child small for gestational age (defined as birth weight <1oth percentile [16]), and perinatal mortality (defined as foetal or neonatal death between 22 weeks of gestation and one week post partum).

Secondary endpoints were the separate components of the composite measure and maternal fatigue and quality of life one month post partum. Fatigue was assessed using the 'Shortened fatigue questionnaire' [17]. Quality of life was assessed using the validated 'EQ5D questionnaire' [18].

\section{Sample size calculation}

Since midwifery in primary healthcare follows strict protocols and serology was performed in one laboratory for all participants the presence of clustering in the infrequent primary outcome of the study was expected to be minimal. Therefore the sample size calculation was performed at the individual level.

Based on the literature and pilot data from the Netherlands, we expected that $12 \%$ of pregnant women in the $Q$ fever high-risk areas would be seropositive $[19,20]$. Of these, we estimated at least $25 \%$ would have one of the previously defined complications. Thus, 3\% of all pregnant women in Q fever high-risk areas would meet the primary outcome. A reduction of the complication rate by at least $50 \%$ as a consequence of early detection through screening during pregnancy was defined as clinically relevant. We considered reductions smaller than $50 \%$ unlikely to trigger a 
Flow chart of the progress of clusters and participants, study on screening for Coxiella burnetii infection during pregnancy, the Netherlands, $2010(\mathrm{n}=1,229)$

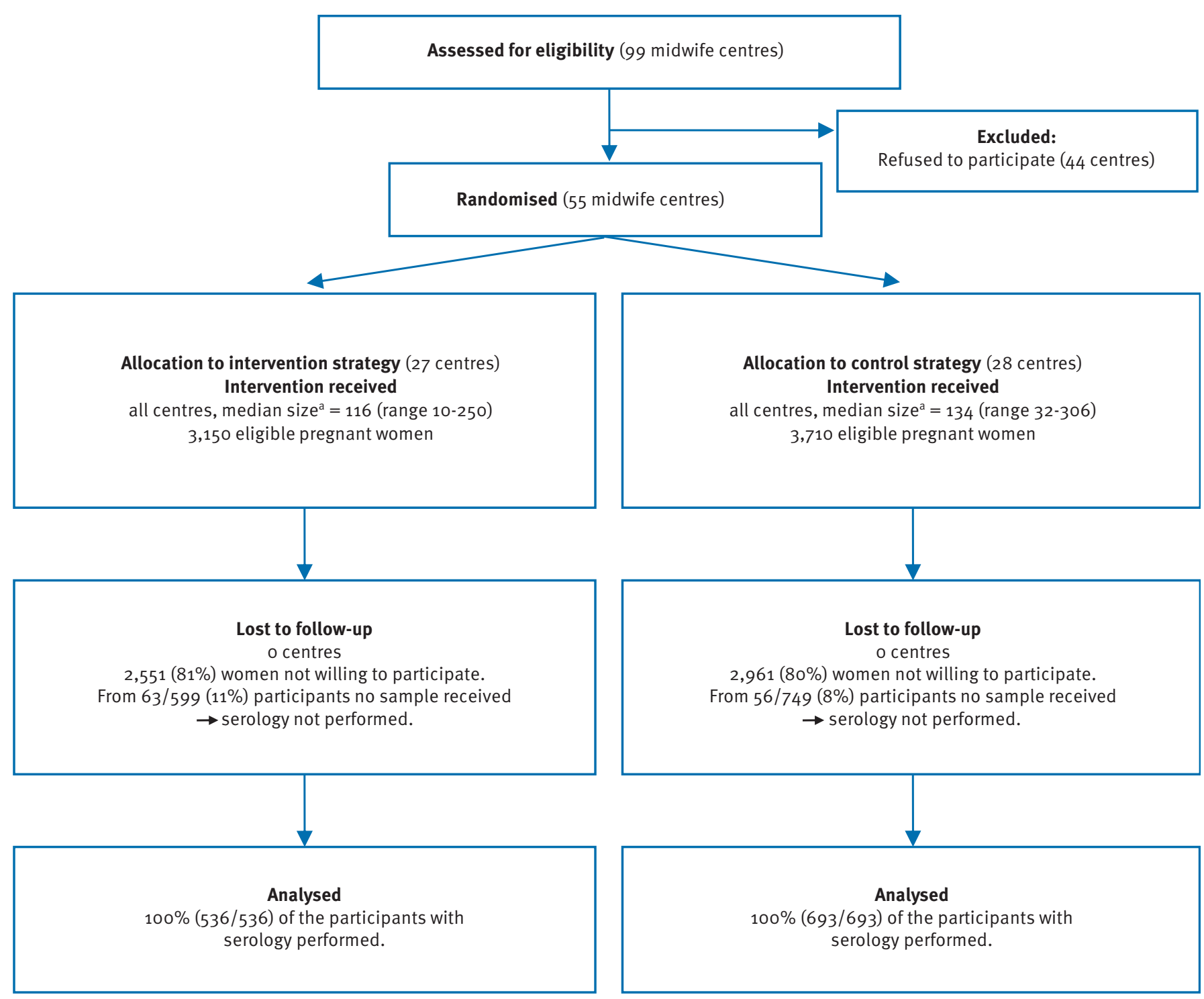

a Size of the midwife centre according to the number of eligible pregnant women under care.

change in practice given the implications on healthcare resources. Based on these expectations, we estimated needing at least 3,400 participants with complete follow-up to achieve a statistical power of $80 \%$ (twosided $a=0.05)$.

\section{Statistical methods}

Data were analysed according to intention-to-screen principle. Baseline demographic information was summarised by group using frequencies with percentages for categorical variables and means with standard deviations for continuous variables. Odds ratios
(OR) and corresponding $95 \%$ confidence intervals (CI) were calculated using generalised linear mixed models (GLMM) to adjust for possible clustering effects. For continuous variables the mean difference with $95 \% \mathrm{Cl}$ was calculated. For the primary endpoint also the crude OR with $95 \% \mathrm{Cl}$ was calculated using binary logistic regression analysis, to provide an indication of the extent of clustering. A two-sided $p$ value of 0.05 or less was defined as being statistically significant. Statistical analyses were performed using $\mathrm{R}$ version 12.1 and PASW Statistics version 18.0 (SPSS inc. Chicago, Illinois, USA). 


\section{TABLE 1}

Baseline characteristics of the clusters $(n=55)$ and participants, study on screening for Coxiella burnetii infection during pregnancy, the Netherlands, $2010(n=1,229)$

\begin{tabular}{|c|c|c|}
\hline & Intervention group (\%) & Control group (\%) \\
\hline \multicolumn{3}{|l|}{ Midwife centre characteristics } \\
\hline Number & 27 & 28 \\
\hline \multicolumn{3}{|l|}{ Size } \\
\hline$\leq 300$ women per year & $14(52)$ & $13(46)$ \\
\hline 3300 women per year & $13(48)$ & $15(54)$ \\
\hline \multicolumn{3}{|l|}{ Goat farms in municipality } \\
\hline$\leq 7$ & $13(48)$ & $14(50)$ \\
\hline$>7$ & $14(52)$ & $14(50)$ \\
\hline \multicolumn{3}{|l|}{ Participant characteristics } \\
\hline Number & 536 & 693 \\
\hline Age (in years) mean \pm SD & $31.9 \pm 3.8$ & $31.7 \pm 3.7$ \\
\hline Nulliparous & $252(47)$ & $295(43)$ \\
\hline Ethnic origin non-western ${ }^{a}$ & $14(2.6)$ & $12(1.7)$ \\
\hline \multicolumn{3}{|l|}{ Level of education ${ }^{b}$} \\
\hline Low & $29(5.4)$ & $49(7.1)$ \\
\hline Medium & $177(33)$ & $228(33)$ \\
\hline High & $319(60)$ & $411(59)$ \\
\hline Other/Unknown & $11(2.1)$ & $5(0.7)$ \\
\hline Maternal smoking during pregnancy & $54(10)$ & $54(7.8)$ \\
\hline Body mass index $\left(\mathrm{kg} / \mathrm{m}^{2}\right)$ mean $\pm \mathrm{SD}^{c}$ & $23.8 \pm 3.7$ & $24.1 \pm 4.0$ \\
\hline Primary hypertension & $5(0.9)$ & $3(0.4)$ \\
\hline Hypothyroidism & $6(1.1)$ & $11(1.6)$ \\
\hline History of preterm delivery & $20(3.7)$ & $24(3.5)$ \\
\hline \multicolumn{3}{|l|}{ History of miscarriage $^{d}$} \\
\hline None & $411(77)$ & $550(79)$ \\
\hline One & $97(18)$ & $115(17)$ \\
\hline Repeated & $27(5.0)$ & $27(3.9)$ \\
\hline Gestational age (weeks) moment of sampling mean \pm SD & $28.7 \pm 4.7$ & $29.9 \pm 4.8$ \\
\hline Coxiella burnetii seropositive & $82(15)$ & $101(15)$ \\
\hline
\end{tabular}

a Non-western is defined as any ethnic background other than Western-Europe, North-American or Australian.

b Low: no formal education, primary school, lower-middle secondary school and lower professional school; medium: medium professional school and higher secondary school; high: higher professional school and university.

c Prior to pregnancy.

d $n=535$ for intervention group and $n=692$ for control group.

\section{Results}

Between March 16 and July 17, 2010, 55 of the 99 eligible midwife centres were willing to participate and were randomised: 27 to the intervention and 28 to the control strategy (Figure 2). In total, these centres supervised 6,860 eligible pregnant women of whom $1,348(20 \%)$ signed informed consent. Among these women a blood sample was collected for 1,229 participants: 536 participants (44\%) in the intervention group and $693(56 \%)$ in the control group. At the moment of screening, none of the participants suffered from clinical signs of symptomatic Q fever [4], such as pneumonia or hepatitis.

Of 119 participants no blood sample was received, either because they forgot to give a sample or because the sample was lost. These women were excluded from the analysis since the primary outcome measure could not be determined. Of 104 participants in the intervention group and 196 participants in the control group, the sample was taken outside the protocol period, i.e. before 20 weeks of gestation $(n=7$ and $n=5$, 
TABLE 2

Complications in seropositive participants, study on screening for Coxiella burnetii infection during pregnancy, the Netherlands, $2010(\mathrm{n}=1,229)$

\begin{tabular}{|c|c|c|c|c|c|c|c|c|}
\hline & \multicolumn{2}{|c|}{ Intervention group } & \multicolumn{2}{|c|}{ Control group } & \multirow[b]{2}{*}{$\begin{array}{l}\text { Unadjusted OR } \\
(95 \% \mathrm{Cl})\end{array}$} & \multirow[b]{2}{*}{ P value ${ }^{a}$} & \multirow[b]{2}{*}{$\begin{array}{c}\text { Adjusted } \\
\mathrm{OR}^{\mathrm{b}}(95 \% \mathrm{Cl})\end{array}$} & \multirow[b]{2}{*}{ P value ${ }^{b}$} \\
\hline & $\begin{array}{c}\text { Total } \\
n=536 \\
(\%)\end{array}$ & $\begin{array}{c}\text { Seropositives } \\
\begin{array}{c}n=82 \\
(\%)\end{array}\end{array}$ & $\begin{array}{c}\text { Total } \\
\mathrm{n}=693 \\
(\%)\end{array}$ & $\begin{array}{l}\text { Seropositives } \\
n=101 \\
(\%)\end{array}$ & & & & \\
\hline Overall complication ${ }^{c}$ & $12(2.2)$ & $12(14.6)$ & $10(1.4)$ & $10(9.9)$ & $\begin{array}{c}1.56 \\
(0.67-3.65)\end{array}$ & 0.30 & $\begin{array}{c}1.54 \\
(0.60-3.96)\end{array}$ & 0.37 \\
\hline Preterm delivery & $8(1.5)$ & $8(9.8)$ & $5(0.7)$ & $5(5.0)$ & $\begin{array}{c}2.09 \\
(0.68-6.41)\end{array}$ & 0.20 & $\begin{array}{c}1.80 \\
(0.37-8.72)\end{array}$ & 0.47 \\
\hline Small for gestational age & $4(0.7)$ & $4(4 \cdot 9)$ & $5(0.7)$ & $5(5.0)$ & $\begin{array}{c}1.04 \\
(0.28-3.87)\end{array}$ & 0.96 & $\begin{array}{c}1.04 \\
(0.28-3.87)\end{array}$ & 0.96 \\
\hline Perinatal mortality & $0(0.0)$ & $0(0.0)$ & $0(0.0)$ & $0(0.0)$ & \multicolumn{4}{|c|}{ Not applicable } \\
\hline
\end{tabular}

$\mathrm{Cl}$ : confidence interval; OR: odds ratio.

a Crude odds ratio and $\mathrm{p}$ value calculated with binary logistic regression analysis.

b Odds ratio and $p$ value calculated with generalised linear mixed models, taking into account a clustering effect.

c Primary outcome measure.

\section{TABLE 3}

Fatigue and quality of life one month post partum for all participants, study on screening for Coxiella burnetii infection during pregnancy, the Netherlands, $2010(n=1,229)$

\begin{tabular}{|c|c|c|c|c|c|}
\hline & $\begin{array}{l}\text { Intervention } \\
\text { group } \\
\mathrm{n}=536(\%)\end{array}$ & $\begin{array}{c}\text { Control group } \\
n=693(\%)\end{array}$ & OR $(95 \% \mathrm{Cl})^{\mathrm{a}}$ & $\begin{array}{l}\text { Mean difference }{ }^{a} \\
(95 \% \mathrm{Cl})\end{array}$ & Pvalue \\
\hline Fatigue score mean $\pm S D^{b}$ & $14.6 \pm 5.7$ & $13.5 \pm 5.5$ & NA & $1.08[0.43-1.72]$ & $<0.001$ \\
\hline \multicolumn{6}{|l|}{ Quality of Life ${ }^{c}$} \\
\hline Mobility $\geq 2$ & $58(12)$ & $86(14)$ & $0.86(0.60-1.23)$ & NA & 0.42 \\
\hline Self-care $\geq 2$ & $3(0.6)$ & $3(0.5)$ & $1.31(0.26-6.50)$ & NA & 0.75 \\
\hline Usual activities $\geq 2$ & $74(15)$ & $99(16)$ & $0.97(0.70-1.35)$ & NA & 0.85 \\
\hline Pain/discomfort $\geq 2$ & $132(27)$ & $179(28)$ & $0.94(0.72-1.24)$ & NA & 0.68 \\
\hline Anxiety/depression $\geq 2$ & $27(5.5)$ & $38(6.0)$ & $0.92(0.56-1.53)$ & NA & 0.75 \\
\hline$E Q V A S \pm^{d}$ & $80.1 \pm 11.6$ & $81.4 \pm 12.1$ & NA & $1.18(-0.39-2.75)$ & 0.14 \\
\hline
\end{tabular}

$\mathrm{Cl}$ : confidence interval; NA: not applicable; OR: odds ratio.

a Odds ratio, mean difference and $\mathrm{p}$ value calculated with generalised linear mixed models, taking into account a clustering effect.

b $n=506$ and 662 for the intervention and control group, respectively. Range of the score from 4 (not fatigue) to 28 (extreme fatigue).

c First part of the 'EQ5D' questionnaire, $n=488$ and 636 for the intervention and control group, respectively. Score of $1=$ no problems, $2=$ with any problems, $3=$ with major problems.

d Second part of the 'EQ5D' questionnaire, self-reported health score on a scale from o to 100 , score of $100=$ best imaginable health state, score $0=$ worst imaginable health state. Participants with a score lower than 11 were excluded $(n=30)$, since a mistake while filling out was assumed. 
Pregnancy outcome for seropositive versus seronegative participants ${ }^{\text {, }}$, study on screening for Coxiella burnetii infection during pregnancy, the Netherlands, $2010(n=1,229)$

\begin{tabular}{|c|c|c|c|c|c|}
\hline & $\begin{array}{c}\text { Seropositive } \\
n=183(\%)\end{array}$ & $\begin{array}{l}\text { Seronegative } \\
n=1,046(\%)\end{array}$ & OR $(95 \% \mathrm{Cl})^{\mathrm{b}}$ & $\begin{array}{c}\text { Mean difference }{ }^{b} \\
(95 \% \mathrm{Cl})\end{array}$ & P value \\
\hline Gestational age at delivery (in weeks) mean \pm SD & $39.6 \pm 1.8$ & $39.7 \pm 1.7$ & NA & $0.12(-0.15-0.38)$ & 0.38 \\
\hline Preterm delivery $<37$ weeks & $13(7.1)$ & $58(5.5)$ & $1.30(0.70-2.43)$ & NA & 0.41 \\
\hline Preterm delivery «34 weeks & $3(1.6)$ & $13(1.2)$ & $1.32(0.37-4.69)$ & NA & 0.66 \\
\hline Birth weight (in grams) mean $\pm S D$ & $3,512 \pm 527$ & $3,507 \pm 546$ & NA & $4.8(-81-90)$ & 0.91 \\
\hline Small for gestational age & $9(4 \cdot 9)$ & $78(7.5)$ & $0.64(0.32-1.30)$ & NA & 0.22 \\
\hline Perinatal mortality & $0(0.0)$ & $6(0.6)$ & \multicolumn{2}{|c|}{ NA } & $0.60^{c}$ \\
\hline Overall complication ${ }^{\mathrm{d}}$ & $22(12)$ & $133(13)$ & $0.94(0.58-1.52)$ & NA & 0.79 \\
\hline
\end{tabular}

\footnotetext{
$\mathrm{Cl}$ : confidence interval; NA: not applicable; OR: odds ratio.

a Using a cut-off titre of $\geq 1: 32$

b Odds ratio, mean difference and $\mathrm{p}$ value calculated with generalised linear mixed models, taking into account a clustering effect.

Calculated with Fisher's exact test, since generalised linear mixed models could not provide a $\mathrm{p}$ value.

d Composite measure of any preterm delivery, small for gestational age, or perinatal mortality.
}

respectively) or after 32 weeks of gestation ( $n=97$ and $n=191)$. However, there was no difference in the baseline and outcome variables between the participants with and without this protocol deviation (data not presented, available from authors on request), hence they were included in the analysis.

\section{Baseline characteristics}

Baseline characteristics are shown in Table 1 . The mean gestational age at the time of sampling was 28.7 weeks for the intervention group and 29.9 weeks for the control group. Fifteen per cent of the women in both groups were seropositive for $C$. burnetii in the first sample taken. Fifty-two of the 1,229 participants had a probable acute infection: $30(5.6 \%)$ in the intervention group and $22(3.2 \%)$ in the control group; 131 participants had a previous infection: 52 (9.7\%) in the intervention group and 79 (11.4\%) in the control group. After follow-up, seven women in the intervention group (1.3\%) were confirmed as having an acute C. burnetii infection and antibiotic treatment was started at a median stage of pregnancy of 28 weeks (range 22-36 weeks) for a duration of one to five weeks, depending on the serological follow-up and term of pregnancy. In the other 23 patients (77\%) with a probable acute infection, follow-up serology ruled out this suspicion and was consistent with a previous infection. Follow-up showed no cases of probable maternal chronic infections in either of the two groups, so only obstetric complications in seropositive women were recorded as an endpoint. None of the women in the intervention or control group were treated with antibiotics during pregnancy for symptomatic $Q$ fever.

\section{Primary endpoint}

For all the participants the primary outcome measure was available. There was no difference in the primary endpoint between the intervention and the control group (Table 2); the risk estimate obtained from the clustered analysis for an obstetric complication in seropositive women in the intervention group compared with the control group was 1.54 (95\% Cl $0.60-$ 3.96). The non-clustered analysis showed a similar OR of 1.56 ( $95 \% \mathrm{Cl} 0.67-3.65)$. There were six cases of perinatal mortality: four foetal deaths and two early neonatal mortalities. For all of them the mothers were seronegative.

\section{Secondary endpoints}

Analyses of the separate components of the composite measure showed that the difference in the primary endpoint in favour of the control group, though nonsignificant, seemed to be the result of a small difference in the risk of preterm delivery (Table 2).

The fatigue score one month post partum was approximately 1 point higher in the intervention group compared with the control group (14.6 versus 13.5, p<0.001). Quality of life did not differ between the two groups (Table 3 ).

Explorative analysis showed that $C$. burnetii seropositivity during pregnancy, even when the cut-off titre for seropositivity was increased to $\geq 1: 64$ (data not shown), 
was not associated with gestational age at delivery, birth weight or any of the defined obstetric complications (Table 4). Of the seven women in the intervention group with an acute infection, two delivered preterm and one delivered a child small for gestational age.

\section{Discussion}

We showed that, during a Q fever outbreak, large-scale routine serological screening for $C$. burnetii infection during pregnancy starting at 20 weeks of gestation seemed not to be associated with a relevant reduction in obstetric complications in seropositive women. Therefore, our data do not support such a preventive programme. This result was due to the low incidence of acute C. burnetii infection (1.3\%), the absence of patients with a probable chronic infection and the fact that $C$. burnetii seropositivity was not associated with adverse pregnancy outcomes.

Surprisingly, we observed that participants of the intervention group had a somewhat higher fatigue score one month post partum than controls. Although the clinical relevance may be questionable, other screening strategies for infectious diseases during pregnancy have shown that screening for, and therefore awareness of, infectious diseases may induce negative psychological effects [21]. Importantly, despite the fact that our study was performed in a $Q$ fever high-risk area and participation of midwife centres was satisfactory $(56 \%)$, the participation rate of pregnant women was unexpectedly low (20\%). Although it's likely that this low percentage reflects a reluctance to take part in a randomised controlled trial, this might also indicate that the acceptance of such a preventive programme among this group might not be straightforward. From an earlier study on this topic we learned that women's appraisal of programme efficacy and convenience, their knowledge about the disease and perceived $\mathrm{Q}$ fever risk is crucial for their intended programme uptake [22].

Since three out of seven women with an acute $C$. burnetii infection in the intervention group had a complication, monitoring of pregnant women diagnosed with $Q$ fever is still advisable and counselling about treatment should be performed. Further studies on monitoring and treatment, especially of symptomatic infected pregnant women, are needed.

\section{Strengths and limitations}

A major strength of our study is that it is the first randomised, prospective study in a community based - non-selected - pregnant population focusing on the effectiveness of routine screening for $C$. burnetii infection. Since the Dutch Q fever outbreak between 2007 and 2010 was unique in its magnitude and duration, we had the opportunity to perform this study in a high-risk area. However, probably due to the drastic veterinary measures taken by the Dutch government, the incidence of acute $C$. burnetii infections steeply declined since 2010 [10]. Inclusion of participants after the second half of 2010 would not have been informative and was perceived as unethical. Therefore, we did not reach our projected number of participants, which increases the risk of a type II error. However, this risk seems to be minimal, because the lower estimate of the $95 \% \mathrm{Cl}$ of the primary outcome (OR 0.60 ) precludes the a priori defined $50 \%$ risk reduction in relevant outcomes.

There are also some further limitations to address. In this study screening started at 20 weeks of gestation. There are two main reasons why we chose this design. First of all, we aimed to avoid treatment with a drug (cotrimoxazole) that is not completely investigated during the most vulnerable phase of pregnancy [23]. Earlier screening and withholding treatment until 20 weeks of gestation was perceived as unethical and therefore not an option. Secondly, at 20 weeks of gestation pregnant women could combine the venepuncture for this study with a structural ultrasound, which is offered to all pregnant women in the Netherlands. With this we intended to increase the participation rate. Because of this design, screening in the first trimester of pregnancy is still untested, and effectiveness of such a strategy cannot be excluded. However, a recent Danish study showed no association between C. burnetii infection and spontaneous abortion up to 22 weeks of gestation [24], indicating that screening earlier in pregnancy would probably also be ineffective.

Given that $44 \%$ of the eligible midwife centres and $80 \%$ of the eligible pregnant women were not willing to participate, it may not be possible to generalise the results. However, since major patient characteristics such as maternal age and proportion of nulliparous women are comparable with other large population based cohort studies from the Netherlands $[25,26]$, we believe the degree of selection bias is minimal and our results are applicable to other $\mathrm{Q}$ fever outbreaks similar to the one in the Netherlands. Nevertheless pregnant women with a non-western ethnicity were underrepresented in our study population so our results should be interpreted with caution for this group, especially because it is known that the seroprevalence in pregnant women with a non-Dutch ethnic background is higher [27].

In the 119 women who signed informed consent, but from whom no blood sample was available, Q fever cases could have been missed. However, participant characteristics and complication rates in this group were similar to the group with a blood sample analysed; therefore the risk of selection bias seems to be low.

Serological screening during pregnancy in general is challenging. A high rate of false-positive tests has been described, especially for IgM assays [28,29]. Furthermore, the specificity of tests may be low if the incidence of the disease is relatively low and the prevalence is relatively high. Of every positive sample the 
titre was determined and we performed serological follow-up of all IgM positive women to prevent treatment of false-positive acute cases.

In contrast to our results, previous studies reported a strong association between undetected and untreated C. burnetii infection during pregnancy and complicated pregnancy outcome $[7,8,30]$. One explanation for this might be that in the previous non-randomised studies, selection bias could have led to an overestimation of the risks. Otherwise, differences in pathogenicity between different $C$. burnetii strains could exist. Genotyping of Dutch samples is ongoing [31]. Since in the Netherlands a relatively high number of chronic $Q$ fever cases have been described in patients with aneurysms [32], it could be hypothesised that the strains involved in the Dutch outbreak are highly virulent for people with underlying vascular diseases, while pregnant women are relatively protected [33]. However, further discussion on this topic is beyond the scope of this paper.

There are also studies in line with our results. In three large studies conducted in Q fever high-risk areas in Denmark, the Netherlands and France no association between seropositivity and complicated pregnancy outcome was found $[24,27,34]$.

\section{Conclusions}

This clustered randomised controlled trial showed that $15 \%$ of the pregnant women in a $\mathrm{Q}$ fever outbreak area were seropositive, but the incidence of acute $C$. burnetii infection was low. Although the broad confidence interval did not exclude a small beneficial effect of screening, routine screening during pregnancy starting at 20 weeks of gestation seems not to be associated with a relevant reduction of obstetric complications in seropositive women. Therefore, in the current setting, this study does not support such a preventive programme.

\section{Acknowledgements}

The authors would like to thank Ms. Barbara C. Boer, Ms. Ilona Bosker and Ms. Anja B. Van den Hengel for their assistance at the participants' service desk and Mr. Petros Pechlivanoglou for statistical support. Furthermore, the authors gratefully thank all midwives, residents, obstetricians, paediatricians and medical microbiologists of the participating centres for their help in patient recruitment and/or data collection.

This work was financially supported by ZonMw, The Netherlands Organisation for Health Research and Development; programme "Effectiviteits- en Doelmatigheidsonderzoek" (grant number 125030014).

Trial registration: ClinicalTrials.gov, identifier NCT01095328 http://clinicaltrials.gov/ct2/show/NCTo1095328?term $=q+f e$ ver+pregnancy\&rank=1

Conflict of interest
Authors' contributions

JMM participated in the design of the study, performed the study, analysed and interpreted the data and drafted the manuscript; ACAPL participated in the design of the study as an expert on laboratory testing and performed the diagnostic analyses; CJCMH participated in the design of the study as an expert on obstetric care; JCEM was responsible for the logistics surrounding laboratory testing; PMS participated in the design of the study as an expert on laboratory testing and performed the diagnostic analyses; WvdH participated in the design of the study as an expert on national public healthcare and performed the data on $Q$ fever risk areas; AR participated in the design of the study as an expert on local health care in the most affected areas of the Netherlands; EdV participated in the design of the study as an expert on paediatrics; RPS participated in the design of the study as an expert on epidemiology; JGA participated in the design of the study as an expert on obstetric care and supervised the analysis and report; EH initiated and designed the study, wrote the grant application, and supervised the data collection, analysis and report. All authors revised the draft manuscript and approved the final manuscript.

None declared. 


\section{References}

1. Schrag SJ, Arnold KE, Mohle-Boetani JC, Lynfield R, Zell ER, Stefonek K, et al. Prenatal screening for infectious diseases and opportunities for prevention. Obstet Gynecol. 2003;102(4):753-6o. http://dx.doi.org/10.1016/ So029-7844(03)00671-9

2. European Centre for Disease Prevention and Control (ECDC). Annual epidemiological report on communicable diseases in Europe 2010. Stockholm: ECDC. 2010; Available from: http:// www.ecdc.europa.eu/en/publications/Publications/1011 SUR_Annual_Epidemiological_Report_on_Communicable Diseases_in_Europe.pdf

3. Schimmer B, Morroy G, Dijkstra F, Schneeberger PM, Weers-Pothoff G, Timen A, et al. Large ongoing $Q$ feve outbreak in the south of The Netherlands, 2008. Euro Surveill. 2008;13(31):pii=18939. Available from: http://www. eurosurveillance.org/ViewArticle.aspx?Articleld=18939

4. Parker NR, Barralet JH, Bell AM. Q fever. Lancet. 2006;367(9511):679-88. http://dx.doi.org/10.1016/ S0140-6736(06)68266-4

5. Hartzell JD, Wood-Morris RN, Martinez LJ, Trotta RF. Q fever: epidemiology, diagnosis and treatment. Mayo Clin Proc. 2008;83(5):574-9. PMid:18452690.

6. Raoult D, Marrie TJ, Mege JL. Natural history and pathophysiology of Q fever. Lancet Infect Dis. 2005;5(4):21926. http://dx.doi.org/10.1016/S1473-3099(05)70052-9

7. Carcopino X, Raoult D, Bretelle F, Boubli L, Stein A. Managing $Q$ fever during pregnancy: the benefits of long-term cotrimoxazole therapy. Clin Infect Dis. 2007;45(5):548-55. http://dx.doi.org/10.1086/520661. PMid:17682987.

8. Langley JM, Marrie TJ, Le Blanc JC, Almudevar A, Resch L, Raoult D. Coxiella burnetii seropositivity in parturient women is associated with adverse pregnancy outcomes. Am J Obstet Gynecol. 2003;189(1):228-32. http://dx.doi.org/10.1067/ mob.2003.448. PMid:12861167.

9. Tissot-Dupont H, Vaillant V, Rey S, Raoult D. Role of sex, age, previous valve lesion and pregnancy in the clinical expression and outcome of $Q$ fever after a large outbreak. Clin Infect Dis. 2007;44(2):232-7. http://dx.doi.org/10.1086/510389. PMid:17173223.

10. Roest HI, Tilburg JJ, Van der Hoek W, Vellema P, van Zijderveld FG, Klaassen $\mathrm{CH}$, et al. The $\mathrm{Q}$ fever epidemic in The Netherlands: history, onset, response and reflection. Epidemiol Infect 2011;139(1):1-12. http://dx.doi.org/10.1017/ So950268810002268. PMid:20920383.

11. National Institute for Public Health and the Environment Gemelde Q-koortspatiënten 2007-2011. [Notified number of Q fever cases 2007-2011, incidence per municipality]. Bilthoven: RIVM; [Accessed Jun 2013]. Available from: http://www.rivm.nl/ dsresource?objectid=rivmp:180268\&type=org\&disposition $=$ in line\&ns_nc $=1$

12. Van der Hoek W, Meekelenkamp JC, Dijkstra F, Notermans DW, Bom B, Vellema P, et al. Proximity to goat farms and Coxiella burnetii seroprevalence among pregnant women. Emerg Infect Dis. 2011;17(12):2360-3. http://dx.doi.org/10.3201/ eid1712.110738. PMid:22172140. PMCid:3311170.

13. Statistics Netherlands. No home internet access for 1.2 million Dutch people. Den Haag: Statistics Netherlands. 18 Dec 2008; Available from: http://www.cbs.nl/en-GB/menu/themas/vrijetijd-cultuur/publicaties/artikelen/archief/2008/2008-2641-wm. htm?Languageswitch=on

14. Meekelenkamp JC, Schneeberger PM, Wever PC, Leenders AC. Comparison of ELISA and indirect immunofluorescent antibody assay detecting Coxiella burnetii IgM phase II for the diagnosis of acute $Q$ fever. Eur J Clin Microbiol Infect Dis. 2012;31(6):1267-70. http://dx.doi.org/10.1007/s10096-0111438-0. PMid:21997772.

15. Wegdam-Blans MC, Kampschreur LM, Delsing CE, BleekerRovers CP, Sprong T, van Kasteren ME, et al. Chronic $Q$ fever: review of the literature and a proposal of new diagnostic criteria. J Infect. 2012;64(3):247-59. http://dx.doi. org/10.1016/j.jinf.2011.12.014. PMid:22226692.

16. Visser GH, Eilers PH, Elferink-Stinkens PM, Merkus HW, Wit JM. New Dutch reference curves for birthweight by gestational age. Early Hum Dev. 2009;85(12):737-44. http://dx.doi. org/10.1016/j.earlhumdev.2009.09.008. PMid:19914013.

17. Alberts M, Smets EMA, Vercoulen JHMM, Garssen B, Bleijenberg G. "Verkorte vermoeidheidsvragenlijst": een praktisch hulpmiddel bij het scoren van vermoeidheid. [Shortened fatigue questionnaire: a practical aid in scoring fatigue]. Ned Tijdschr Geneeskd. 1997;141(31):1526-30. Dutch. PMid:9543741.

18. Centre for Health Economics, University of York. The EuroQoL Group. EuroQol: A new facility for the measurement of health-related quality of life. Health Policy. 1990;16(3):199208. http://dx.doi.org/10.1016/0168-8510(90)90421-9.

19. Karagiannis I, Schimmer B, Van Lier A, Timen A, Schneeberger $P$, Van Rotterdam B, et al. Investigation of a $Q$ fever outbreak in a rural area of the Netherlands. Epidemiol Infect 2009;137(9):1283-94. http://dx.doi.org/10.1017/ So950268808001908. PMid:19161644.

20. Meekelenkamp JCE, Notermans DW, Rietveld A, Marcelis JH, Schimmer B, Reimerink JHJ, et al. Seroprevalence of Coxiella burnetii in pregnant women in the province of Noord-Brabant in 2007. Infectieziekten Bulletin. 2009;20(2):57-61. Dutch.

21. Melville J, Sniffen S, Crosby R, Salazar L, Whittington W, Dithmer-Schreck D, et al. Psychosocial impact of serological diagnosis of herpes simplex virus type 2 : a qualitative assessment. Sex Transm Infect. 2003;79(4):280-5. http://dx.doi.org/10.1136/sti.79.4.280. PMid:12902574. PMCid:1744709.

22. Breteler JK, Oudhoff JP, Munster JM, Aarnoudse JG, van Steenbergen JE, Beaujean DJ. Risks, trust and knowledge: determinants of pregnant women's decisions regarding participation in a future $\mathrm{Q}$ fever screening and treatment program during a large epidemic in The Netherlands. Prenat Diagn. 2011;31(8):814-20. http://dx.doi.org/10.1002/pd.2772. PMid:21717482.

23. Hernández-Díaz S, Werler MM, Walker AM, Mitchell AA. Folic acid antagonists during pregnancy and the risk of birth defects. N Engl J Med. 2000;343(22):1608-14. http://dx.doi. org/10.1056/NEJM200011303432204. PMid:11096168.

24. Nielsen SY, Hjøllund NH, Andersen AM, Henriksen TB, Kants $\emptyset$ B, Krogfelt KA, et al. Presence of antibodies against Coxiella burnetii and risk of spontaneous abortion: a nested case-control study. PLoS One. 2012;7(2):e31909. http:// dx.doi.org/10.1371/journal.pone.0031909. PMid:22363769. PMCid:3283715.

25. Ravelli AC, Jager KJ, de Groot MH, Erwich JJ, Rijninks-van Driel GC, Tromp M, et al. Travel time from home to hospital and adverse perinatal outcomes in women at term in the Netherlands. BJOG 2011;118(4):457-65. http://dx.doi. org/10.1111/j.1471-0528.2010.02816.x. PMid:21138515.

26. Tromp M, Eskes M, Reitsma JB, Erwich JJ, Brouwers HA Rijninks-van Driel GC, et al. Regional perinatal mortality differences in the Netherlands; care is the question. BMC Public Health. 2009;9:102. http://dx.doi.org/10.1186/1471 2458-9-102. PMid:19366460. PMCid:2674436.

27. Van der Hoek W, Meekelenkamp JCE, Leenders ACAP, Wijers N, Notermans DW, Hukkelhoven CW. Antibodies against Coxiella burnetii and pregnancy outcome during the 2007-2008 Q fever outbreaks in the Netherlands. BMC Infect Dis. 2011;11:44. http://dx.doi.org/10.1186/1471-2334-11-44. PMid:21314933. PMCid:3042933.

28. De Carolis S, Santucci S, Botta A, Garofalo S, Martino C, Perrelli $A$, et al. False-positive IgM for CMV in pregnant women with autoimmune disease: a novel prognostic factor for poor pregnancy outcome. Lupus 2010;19(7):844-9. http://dx.doi. org/10.1177/0961203310361350. PMid:20305050.

29. Jones JL, Krueger A, Schulkin J, Schantz PM. Toxoplasmosis prevention and testing in pregnancy, survey of obstetriciangynaecologists. Zoonoses Public Health. 2010;57(1):2733. http://dx.doi.org/10.1111/j.1863-2378.2009.01277.x. PMid:19744302.

30. Stein A, Raoult D. Q fever during pregnancy: a public health problem in Southern France. Clin Infect Dis. 1998;27(3):592-6. http://dx.doi.org/10.1086/514698

31. Huijsmans CJ, Schellekens JJ, Wever PC, Toman R, Savelkoul $\mathrm{PH}$, Janse I, et al. SNP-genotyping of a Coxiella burnetii outbreak in the Netherlands. Appl Environ Microbiol. 2011;77(6):2051-7. http://dx.doi.org/10.1128/AEM.02293-10. PMid:21257816. PMCid:3067327.

32. Wever PC, Arts CH, Groot CA, Lestrade PJ, Koning OH, Renders $\mathrm{NH}$. Screening for chronic $\mathrm{Q}$ fever in symptomatic patients with an aortic aneurysm or prosthesis. Ned Tijdschr Geneeskd. 2010;154:A2122. Dutch. PMid:20699030.

33. Angelakis E, Million M, D’Amato F, Rouli L, Richet H, Stein A, et al. $Q$ fever and pregnacy: disease, prevention, and strain specificity. Eur J Clin Microbiol Infect Dis. 2013;32(3):361-8. http://dx.doi.org/10.1007/s10096-012-1750-3. PMid:23052984.

34. Rey D, Obadia Y, Tissot-Dupont H, Raoult D. Seroprevalence of antibodies to Coxiella burnetii among pregnant women in South Eastern France. Eur J Obstet Gynecol Reprod Biol. 2000;93(2):151-6. http://dx.doi.org/10.1016/ So301-2115(00)00276-1 